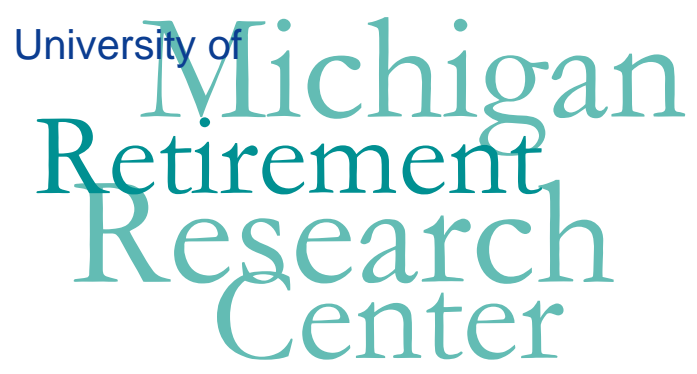

Working Paper WP 2005-100

\title{
Knowledge and Preference in Reporting Financial Information
}

Honggao Cao and Daniel H. Hill

\begin{tabular}{|l|l|}
\hline $\mathrm{M}$ & $\mathrm{R}$ \\
\hline $\mathrm{R}$ & $\mathrm{C}$ \\
\hline
\end{tabular}$\quad$ Project \#: UM04-10 


\title{
"Knowledge and Preference in Reporting Financial Information"
}

\author{
Honggao Cao \\ University of Michigan \\ Daniel Hill \\ University of Michigan
}

April 2005

\author{
Michigan Retirement Research Center \\ University of Michigan \\ P.O. Box 1248 \\ Ann Arbor, MI 48104
}

\section{Acknowledgements}

This work was supported by a grant from the Social Security Administration through the Michigan Retirement Research Center (Grant \# 10-P-98358-5). The findings and conclusions expressed are solely those of the author and do not represent the views of the Social Security Administration, any agency of the Federal government, or the Michigan Retirement Research Center.

Regents of the University of Michigan

David A. Brandon, Ann Arbor; Laurence B. Deitch, Bingham Farms; Olivia P. Maynard, Goodrich; Rebecca McGowan, Ann Arbor; Andrea Fischer Newman, Ann Arbor; Andrew C. Richner, Grosse Pointe Park; S. Martin Taylor, Gross Pointe Farms; Katherine E. White, Ann Arbor; Mary Sue Coleman, ex officio 


\title{
Knowledge and Preference in Reporting Financial Information
}

\author{
Honggao Cao and Daniel Hill
}

\begin{abstract}
This article models respondent behavior in a financial survey with a framework explicitly integrating a respondent's knowledge of and willingness to reveal his or her financial status. Whether a respondent provides a valid answer, a “don't know”, or a "refusal” to a financial question depends on the interaction of his or her financial knowledge and preferences regarding revealing the knowledge. Using asset response and nonresponse data from the Health and Retirement Study (2000), we found that knowledge and preferences play interrelated roles in reporting financial information, that a respondent's age, gender, education, and race and ethnicity are important predictors of respondent behavior, and that race and ethnicity affect a respondent behavior only via their influence on preferences, while gender only via its influence on knowledge. We also found strong heterogeneity in respondents' financial knowledge and their willingness to reveal the knowledge.
\end{abstract}

\section{Keywords:}

Item nonresponse, respondent behavior model, don't know, refusal, asset survey, HRS 


\section{Introduction}

One of the problems in collecting financial information in a survey is generally high nonresponse rates. Conditional on asset ownership, for example, $42 \%$ of respondents did not provide the dollar value of stock in the Survey of Income and Program Participation (SIPP), 32\% of respondents did not provide the value of their checking account in the Panel Study of Income Dynamics (PSID), and 26\% of respondents did not provide value of Bonds in the Survey of Consumer Finances (SCF) (Chand and Gan, 2002). Two reasons are often offered to explain why collection of financial information is inherently difficult (Loosveldt, Pickery, and Billet, 1999; Fries, Starr-McCluer, and Sundén, 1998; Juster and Smith, 1997). First, respondents may not know the answers to the financial questions presented, due to either a lack of full knowledge of their financial situations, or their difficulties in understanding the questions. This problem shares the same feature as when collecting other type of information. Second, respondents who know the answers to the financial questions may prefer not to reveal them in the survey due to their concerns about their financial privacy. This problem is quite unique as an individual's financial information is among the most closely guarded secrets (AARP, 2002), and those at the top end of the wealth distribution are generally less willing to disclose their financial status (Juster and Smith, 1997).

While the immediate consequences of the two problems for the quality of financial data appear to be same (i.e., missing data), the roles of knowledge and preference in determining an individual's response (or nonresponse) behavior to financial questions are perhaps very different. Based on the Health and Retirement Study (HRS) and the Asset and Health Dynamics Among the Oldest Old (AHEAD), for example, Juster and Smith (1997) found that, compared to those who refused to disclose the values of their assets, respondents who said "I don't know" to an 
asset question were more likely to provide definitive answers to ensuing bracket questions. Based on the bracket information, the mean asset values of the latter group were also significantly lower. Similarly, using German Socio-Economic Panel, Riphahn and Serfling (2004) find that the characteristics of "don't know" respondents were neither close to those providing informative answers nor to those refusing to respond, or "refusal" respondents.

The evidence that "don't know" and "refusal" respondents are different raises a series of important issues. Why are they different? How different are they? Are there any mechanisms to distinguish them prior to survey? How can a future survey design take into account the differences to reduce nonresponse rates to financial questions? In this article we attempt to address some of these issues. Specifically we use asset nonresponse data in the Health and Retirement Study 2000 (HRS 2000) to validate the relationship between "don't know" and "refusal" respondents, to identify key factors in determining the two group's nonresponse behavior, and to explore possible strategies to reduce nonresponse rates for each of the groups. We do all of these in a simple model focusing on respondents' integration and calculation of their knowledge about and preference to conceal their financial situations. We distinguish "don't know" and "refusal" respondents based on an intuitively straightforward assumption: To provide a definitive answer to an asset question, a respondent has to have certain amount of information or knowledge about the financial asset (knowledge threshold), and have certain level of willingness to reveal the value of his or her financial asset (preference threshold). Naturally, according to this assumption, whether a nonresponse comes from "don't know" or "refusal" depends on a respondent's failure to reach the knowledge or preference threshold.

Modeling survey nonresponse in a framework focusing on knowledge and preference is not new in the literature. In the cognitive model of respondent behavior (Sudman, Bradburn, and 
Schwarz, 1996; Tourangeau, 1984; Tourangeau, Rips, and Ransinki, 2000), information integration and knowledge editing are important stages of cognitive processing. In the rational choice model (Esser, 1993; Sirken, Willis, and Nathan, 1991), whether a respondent participates in a survey or answers a question depends on his or her calculation of utility associated with each alternative. As we will see below, our model — while essentially related to both of the modelshas several new elements.

The rest of the article is organized as follows. Section II reviews prior research on item nonresponse. This review will help us select explanatory variables in our empirical work. Section III presents our "knowledge and preference" model of item nonresponse. Section IV describes the HRS 2000 asset response and nonresponse data, while Section V reports empirical findings. The article concludes in Section VI with a discussion of the results found in the analysis.

\section{Prior Research on Item Nonresponse}

Respondent behavior in interviews has been a subject of research in a large body of literature. Among various frameworks used in this research, two stand out. The first is the cognitive model (Sudman, Bradburn, and Schwarz, 1996; Tourangeau, 1984; Tourangeau, Rips, and Ransinki, 2000), which sees a respondent behavior in interview as consisting of several stages of cognitive processing. These include interpreting the interview question to understand what it means, collecting information relevant to the question, translating the information into judgment, and formatting and editing an answer to the question. In this process, information retrieving and integration play an important role in forming an answer internally. But whether the respondent provides a response and - if yes — whether he or she completely reveals his or her 
answer to the question depend on his or her formatting and editing, which is in turn a function of his or her value judgment or preference.

A second framework that has also been cited widely in the literature of respondent behavior is the rational choice model (Esser, 1993; Sirken, Willis, and Nathan, 1991). Unlike the cognitive model, which focuses on the process of response formation and editing, the rational choice model focuses on utility comparison between the two alternatives facing the respondent: to answer or not to answer a question. After having heard (or read) and understood a question, a respondent chooses to answer it - the model goes - if he or she believes that the utility derived from answering the question is greater than the utility derived from not answering the question. Conversely, a respondent chooses not to answer the question if the utility derived from this alternative is greater.

Within the above two general frameworks, studies of item nonresponse have covered a wide range of issues. One key area of the studies is their focus on the effects of respondent and question characteristics. Two important respondent characteristics often examined in this context are age and education, which are related to respondent behavior via a basic premise that respondents with higher level of cognitive sophistication produce less item nonresponse (Ferber, 1996; Groves, 1989). In general, older respondents tend to provide more item nonresponse, and more education tends to produce less item nonresponse, although some studies (Murata and Gwartney, 1999, for example) also found more education tended to lead to higher item nonresponse, especially for women and Hispanics.

The effect of question characteristics on item nonresponse becomes a focus of many studies because question characteristics impact respondent ability (or cost) to understand questions and produce a response. "When the response task requires recall of many separate 
entities or arithmetic or logical combinations of them, some respondent may terminate their cognitive processing prematurely." (Groves, 1989, p. 432) As such, the rate of item nonresponse increases with the complexity or difficulty of questions facing respondents.

Another important area of emphasis in the studies of item nonresponse is on the relationship between the respondent and the interviewer as well as interview mode. The key here is about the role of respondent-interviewer interaction in the process of response generation: whether trust between respondent and interviewer can be established so the cost of revealing information becomes lower, whether the similarity in personal characteristics between respondent and interviewer can increase respondent comfort or benefits in providing information. While the empirical evidence is not completely consistent in this area, the overall picture seems to suggest that compared to face-to-face interview, item nonresponse rate is lower in mail-in or "drop-off" survey (Essig and Winter, 2003), and that respondents seem to be much more uncooperative in front of female interviewers than males (Schräpler, 2004).

In summary, previous research on respondent behavior in general and item nonresponse in particular emphasizes in varying degrees the roles of knowledge (or cognitive) processing, and balancing costs and benefits associated with response generation. No attempt has been made, however, to model item nonresponse explicitly based on a respondent's knowledge of and willingness to reveal answers to survey questions. Our "knowledge and preference" model presented below intends to fill this gap.

\section{The Model}

Consider a representative respondent $i$ whose knowledge of asset $j, K_{i j}$, is determined by a vector of personal characteristics $X_{i}^{k}$, and a vector of characteristics of the asset, $Y_{i}^{k}$. That is, 


$$
K_{i j}=\alpha_{1} X_{i}^{k}+\beta_{1} Y_{i}^{k}+\varepsilon_{\mathrm{ij}}^{\mathrm{k}},
$$

where $\varepsilon_{\mathrm{ij}}{ }^{\mathrm{k}}$ is a stochastic error term to be defined shortly, and $\alpha_{1}$ and $\beta_{1}$ are vectors of coefficients corresponding to $X_{i}^{k}$ and $Y_{i}^{k}$, respectively. Similarly, the respondent's willingness to reveal the value of his asset, $P_{i j}$, is also determined by a vector of personal characteristics $X_{i}^{\mathrm{p}}$, and a vector of characteristics of the asset, $Y_{i}^{\mathrm{p}}$ :

$$
P_{i j}=\alpha_{2} X_{i}^{\mathrm{p}}+\beta_{2} Y_{i}^{\mathrm{p}}+\varepsilon_{\mathrm{ij}}^{\mathrm{p}} .
$$

The error terms $\varepsilon_{\mathrm{ij}}{ }^{\mathrm{k}}$ and $\varepsilon_{\mathrm{ij}}{ }^{\mathrm{p}}$ are the results of individual idiosyncrasies and unmeasured variables which should be in the $\mathrm{X}$ and $\mathrm{Y}$ vectors. These terms are assumed to be drawn from the following bivariate normal density:

$$
f\left(\varepsilon_{\mathrm{ij}}{ }^{\mathrm{k}}, \varepsilon_{\mathrm{ij}}^{\mathrm{P}}\right)=A x \exp \left[\left(\mathrm{v}_{\mathrm{k}}{ }^{2}-2 \rho \mathrm{v}_{\mathrm{k}} \mathrm{v}_{\mathrm{p}}+\mathrm{v}_{\mathrm{p}}{ }^{2}\right) /\left(2\left(1-\rho^{2}\right)\right],\right.
$$

where $A$ is a constant equal to $\left\{1 /\left[2 \pi \sigma_{\mathrm{k}} \sigma_{\mathrm{p}}\left(1-\rho^{2}\right)^{1 / 2}\right]\right\}, \mathrm{v}_{\mathrm{k}}=\left(\varepsilon_{\mathrm{ij}}{ }^{\mathrm{k}}-\mu^{\mathrm{k}}\right) / \sigma_{\mathrm{k}}, \mathrm{v}_{\mathrm{p}}=\left(\varepsilon_{\mathrm{ij}}^{\mathrm{P}}-\mu^{\mathrm{P}}\right) / \sigma_{\mathrm{p}}, \mu^{\mathrm{k}}, \sigma_{\mathrm{k}}$, $\mu^{\mathrm{P}}$, and $\sigma_{\mathrm{p}}$ are the means and standard deviations of $\varepsilon_{\mathrm{ij}}{ }^{\mathrm{k}}$ and $\varepsilon_{\mathrm{ij}}{ }^{\mathrm{P}}$, respectively, and $\rho$ is the correlation between $\varepsilon_{i j}{ }^{\mathrm{k}}$ and $\varepsilon_{\mathrm{ij}}^{\mathrm{P}}$.

The respondent provides definitive answers to the asset questions if and only if both $K_{i j}$ and $P_{i j}$ exceed, respectively, the knowledge and preference thresholds, which are both normalized to be zero for simplicity. Conversely, the respondent gives a "don't know" answer to the asset question if $K_{i j}$ does not exceed the knowledge threshold, and refuses to answer the asset question if $P_{i j}$ does not exceed the preference threshold.

The respondent's behavior can best be seen in the following diagram. When the respondent is in the first quadrant of the Knowledge-Preference plane, both his knowledge of the asset value and his willingness to reveal it exceed their respective thresholds, 0 . In this scenario, he provides definitive answer to the asset question. When the respondent is in the second quadrant, his knowledge of the asset is below the knowledge threshold, even though he would be 
willing to reveal its value if he knew it. In this scenario, he gives a "don't know" answer to the asset question. When the respondent is in the fourth quadrant, he knows the value of his asset, but his willingness to reveal it is below the preference threshold. In this scenario, he refuses to answer the asset question. The respondent behavior in the third quadrant, when neither the knowledge nor the preference threshold is met, can be quite murky, depending on the relative failure of his knowledge (or preference) to meet the knowledge (or preference) threshold.

\section{Figure 1. The Respondent Behavior in a Knowledge} and Preference Model

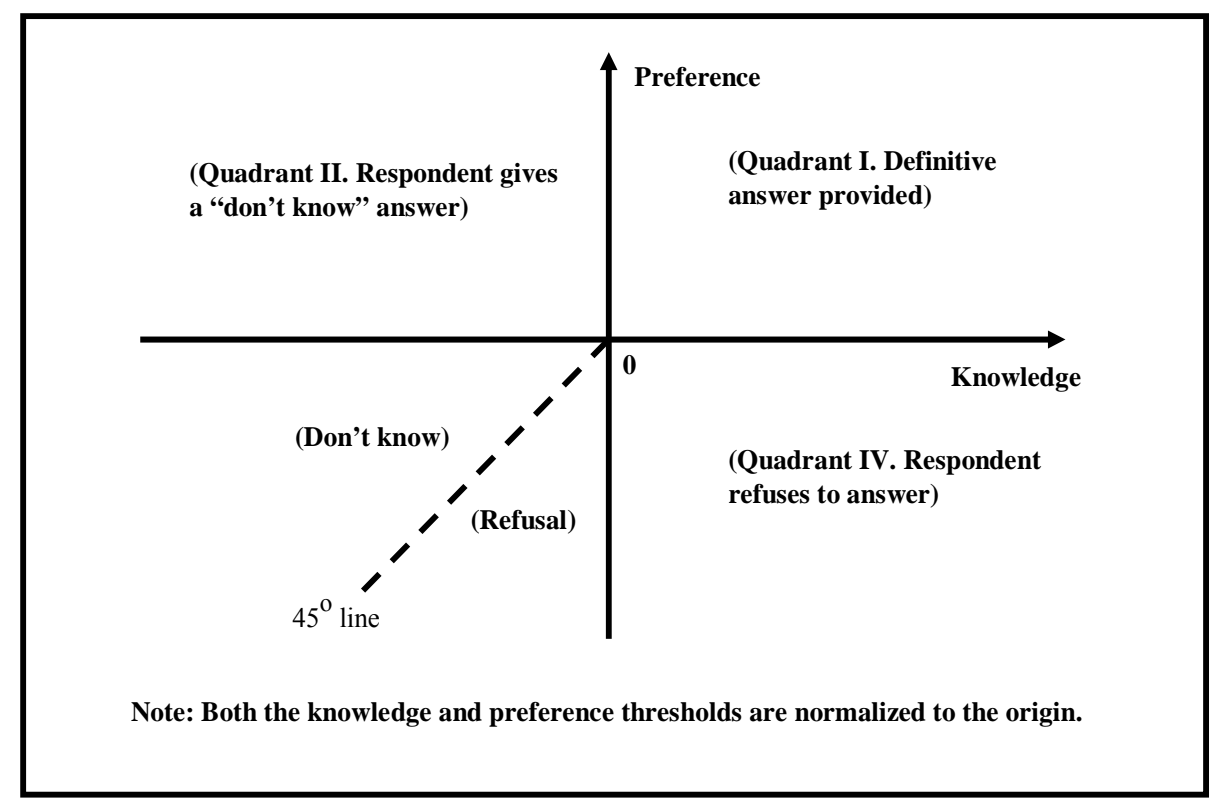

Notice that our model given in (1)-(3) is different from many seemingly similar models that also explicitly explore the distinction between "don't know" and "refusal". In one such model (Riphahn and Serfling, 2002), "don't know" and "refusal" are examined as two alternative outcomes in a three-outcome (the other being definitive response) multinomial logit model. In another case (Schräpler, 2004), whether a respondent provides a definitive answer, a "don't 
know", or an outright refusal depends on the difference between the utility associated with "don't know" and "refusal".

Our model also has the ability to test the interdependence between the knowledge and preference determination processes. This can be done by looking at the correlation between the two error terms, $\rho$. If the correlation is strong and statistically significant, the two processes should be considered interrelated. Conversely, if the correlation is weak or statistically insignificant, the two processes could perhaps been treated as independent.

\section{The HRS 2000 Asset Response and Nonresponse Data}

We used the asset response and nonresponse data in the Health and Retirement Study 2000 (HRS 2000) to test our model. A national longitudinal survey of older Americans that aims to "provide data for researchers, policy analysts, and program planners who are making major policy decisions that affect retirement, health insurance, saving and economic well-being" (HRS, 2004), the HRS contains rich information on respondents' financial assets. In each wave of the HRS, which is a biennial survey starting in 1992, respondents were first asked about the ownership and then the value of such assets as real estate, business and farm, IRA, stock and mutual fund, and transportation vehicle. ${ }^{1}$ For each type of the assets, their answers to these questions ranged from complete reports (definitive answers to both the ownership and value questions), to reports mixed with brackets (definitive answer to the ownership question, "don't know" or "refusal" to the value question, and definitive answers to all or some of the ensuring bracket questions), to definitive report on the ownership only, to no definitive information at all ("don't know" or "refusal" to the ownership question). Because of a nested structure of these

\footnotetext{
${ }^{1}$ These respondents are often termed as "financial respondents" in the HRS. In general, there is only one financial respondent per household.
} 
questions, which is illustrated in Figure 2 for stock and mutual funds, some respondents had multiple opportunities to provide nonresponses to the questions for each asset, with the number of opportunities to provide nonresponses determined by whether a respondent had the asset, and-when he or she had asset--how the respondent answered the ownership question.

Figure 2. The Nested Structure of HRS Asset Questions: Stock and Mutual Funds

1. Do you have any shares of stock or mutual funds?

$\begin{array}{lll}\text { 1. YES } & \text { 2. NO 8. DK } \quad \text { 9. RF } \\ \text { 2. If you sold all of those and paid off anything you owed on them, about how much would you have? }\end{array}$

8. DK
${ } \downarrow }$

3a. Would it amount to less than $\$ 2,500$, more than $\$ 2,500$, or what?

1. LESS THAN \$2,500 3. ABOUT \$2,500 5. MORE THAN \$2,500 8. DK 9. RF

3b. Would it amount to less than $\$ 25,000$, more than $\$ 25,000$, or what?

1. LESS THAN \$25,000 3. ABOUT \$25,000 5. MORE THAN \$25,000 8. DK 9. RF

3c. Would it amount to less than $\$ 125,000$, more than $\$ 125,000$, or what?

1. LESS THAN \$125,000 3. ABOUT \$125,000 5. MORE THAN \$125,000 8. DK 9. RF

3d. Would it amount to less than $\$ \mathbf{4 0 0 , 0 0 0}$, more than $\$ 400,000$, or what?

1. LESS THAN $\$ 400,000 \quad$ 3. ABOUT $\$ 400,000 \quad$ 5. MORE THAN $\$ 400,000 \quad$ 8. DK $\quad$ 9. RF

Note: Illustration only. Consult the HRS survey instrument for the exact structure of the asset questions.

To avoid over-representation of those with multiple nonresponses, we collapsed a respondent's answers to all the questions related to each asset into one single outcome: complete valid response, don't know, or refusal. In addition, complete valid responses (i.e., zeros) from those not owning an asset were eliminated from our analysis on the ground that retrieving the knowledge of not owning an asset requires little cognitive processing and revealing such information may not be a big problem for respondents concerned about their financial privacy. 
The differentiation between "don't know" and "refusal" outcomes needs more explanation. As a general rule, we classified a respondent's answers as "don't know" if the respondent provided a "don't know" answer to the ownership question, or —with a "yes" answer to the ownership question - provided a "don't know" answer to the value question. The "refusal" outcome was defined in a similar way. This classification rule ignored the impact of different types of nonresponses to the bracket questions that were followed for those who gave "don't know" or "refusal" to the value question. Specifically, no special treatment was given to those who gave "don't know" (or "refusal") answer to the value question but "refusal" (“don't know") to the bracket questions. We found that such changes in nonresponse behavior to the questions within each asset group to be rare (less than $0.5 \%$ ), however.

We pooled together the outcome data defined above for the following ten types of assets: real estate, businesses and farms, IRAs, stocks and mutual funds, bonds, checking and savings accounts, CDs, vehicles, other assets (e.g., jewels, coin collections, etc.), and debts. The summary statistics of these data are given in Table 1.

For explanatory variables, we included age, gender, education, and race and ethnicity dummies in both the knowledge and preference equations. Presumably these variables would capture the effects of respondent characteristics on the knowledge and preference determination. We also included in both equations total household assets at the time of interview, a dummy variable indicating whether a respondent had a spouse, and a dummy variable whether the interview was conducted face-to-face or via telephone. The total asset measure was an aggregation of the ten asset components described above, based on the imputation data produced by the HRS (Cao, 2001). The spouse dummy was intended to check whether the presence of a spouse would affect a respondent's knowledge of his or her financial situation as well as his or 
her willingness to reveal the information. The interview mode dummy was to capture the effect of interview mode on respondent behavior found in many previous studies. Because the HRS 2000 interviews were conducted predominantly via telephone ( more than $85 \%$ ), however, the interview mode effect—if any — may not be seen in our model.

In the knowledge equation, we also included an index indicating a respondent's cognitive ability. Similar to an approach used by Knäuper, Belli, Hill, and Herzog (1997), this index was created by aggregating information from "immediate recall", "series $7 \mathrm{~s}$ test", and "measures of knowledge, language, and orientation". Specifically, in the "immediate recall", respondents were first given ten short, concrete and high-frequency nouns and then asked to recall as many of them as possible. In the "series $7 \mathrm{~s}$ test", respondents were asked to start at 100 and subtract by increments of seven for five trials. One point was given for each correct subtraction for a maximum of five points. In the "measures of knowledge, language, and orientation", respondents were asked to count backwards from 20 for 10 continuous numbers, to name the day of the week and the date, to name the objects that "people usually use to cut paper" and the "kind of prickly plant that grows in the desert" ${ }^{2}$, and to name the president and vice president of the United States. The cognitive ability index used in the knowledge equation was constructed by summing up the raw scores from the three different test domains.

In the preference equation, we included a measure of respondent tendency to reveal private information. A dummy variable indicating whether a respondent gave his or her permission for the HRS to link with his or her pension data was used for this measure.

\footnotetext{
${ }^{2}$ This question caused some problems mostly for Hispanic respondents living in the desert Southwest who differentiate between various species of cacti.
} 
Finally, in both the knowledge and preference equations we included nine asset dummies (with "debt" being the reference) to test the heterogeneity of respondent financial knowledge and preference. This heterogeneity has been reported as recently as in Riphahn and Serfling (2004).

The summary statistics of the explanatory variables are given in Table 1, Panel B.

\section{The Results}

We report the bivariate probit regression results in Table 2. Respondents' financial knowledge and their willingness to reveal it are strongly correlated. The direction of the correlation, however, is negative, suggesting that respondents respondents more knowledgeable about their financial assets than we would expect based on their characteristics are more likely (than we would expect) to keep their financial information from the interviewers. This strong, negative correlation between the two processes is somewhat surprising since in survey research conventional wisdom has it that some "don't knows" are really "soft refusals'. Conversely, some refusals may reflect respondent ignorance which they do not want to reveal regarding the answer. The simple correlation between the two variables is only -..148, while the correlation found in our model is -.962 .

The strong, negative correlation between the two processes does not necessarily imply that "don't know" and "refusal" should be treated as similar nonresponses. But this result does have an ominous implication for survey research on financial data: It is more difficult to collect accurate financial information from those more financially knowledgeable. The adverse effect of nonresponses on the quality of financial data collected is perhaps larger than what we think.

In terms of the effects of respondent characteristics, age is statistically significant in both the knowledge and preference equations. As respondents get older, not only do they lose some 
financial knowledge, they also become more reluctant to reveal what they know about their financial assets even after controlling for cognition and pension plan linkage. This result is reasonable, and generally consistent with those found in the previous research.

Gender effect is present only in the knowledge equation. Compared to female respondents, males tend to be more knowledgeable financially, but show no difference in their willingness to disclose their financial situations.

On the other hand, race and ethnicity effects are present only in the preference equation. Compared to others, Black respondents are less willing to reveal the values of their financial assets, while Hispanic respondents tend to do the opposite.

Education plays a predictable role in the knowledge equation: Respondents with more education are more knowledgeable about their financial assets (Kim, 2001). But it has no impact on their willingness to reveal their financial information.

Among other variables included in both the knowledge and preference equations, total household asset value has no impact in either equation; respondents in coupled households tend to be less knowledgeable about and less willing to reveal their financial information; and compared to telephone interviews, face-to-face interviews have no effect in the knowledge equation, but tend to increase respondents' willingness to reveal their financial information.

The evidence that respondents from coupled households are less knowledgeable and less willing to reveal their financial situations may be explained as follows. Managing household finance is a shared responsibility in a coupled household. One respondent-even the more knowledgeable one ${ }^{3}$ - may not know all the financial activities ongoing in the household. In

\footnotetext{
${ }^{3}$ HRS collects financial data from a "financial respondent" who is presumably more knowledgeable than the other, non-financial respondent in a two-respondent household.
} 
addition, because of the presence of his or her spouse, a respondent may have to take into account the spouse's concern about financial privacy when disclosing their financial information.

The interview mode effect in the preference equation can have ambiguous implications for the survey research. On the one hand, it is encouraging to see that interviewers matter in the field, having a positive impact on respondents' willingness to reveal their financial information. On the other hand, concerned with cost-efficiency and armed with technological development, survey research has gradually obliterated face-to-face interviews, essentially forfeiting the potential benefits associated therewith.

Higher cognitive ability is linked with more financial knowledge, whereas respondents who tend to hide private information (such as pension) are indeed more reluctant to reveal their financial information. These results are obviously consistent with intuition.

Finally, strong heterogeneity in respondents' financial knowledge and their willingness to reveal the knowledge is found in our model. Overall, respondents are less sure about any of their positive assets than about their debts. Compared to their knowledge about debts, the financial assets about which they are least sure are business and farm and bond. They also have trouble in knowing stock and mutual fund, and "other assets". The two positive assets about which they are most knowledgeable are checking and savings accounts, and vehicle, both of which are closely tied to their day-to-day life.

Interestingly respondents are more willing to reveal information on debts than they are on most of their positive assets. In many cases these debts consist of credit card debt and do not include mortgages. There also seems to be a tendency for respondents to reveal assets that are relatively apparent or are matters of public record. For instance, vehicles can be seen by anyone who cares to look, and the (assessed) value businesses and farms can generally be obtained from 
public tax records. Assets such as bonds, CDs and stock and mutual funds are more private and respondents seem more apt to want to keep them that way.

\section{Conclusion}

Knowledge and preference play interrelated roles in reporting financial information. This is a result clearly shown in our analysis. In a model explicitly exploring nonresponse behavior, and using response and nonresponse data for the HRS 2000 financial assets, we found that nonresponses classified as "don't know" and "refusal" were strongly and negatively correlated. Thus, respondents more knowledgeable about their financial information may be more reluctant to reveal what they know. The negative impact of item-nonresponse on the quality of financial data is perhaps larger than what we think.

We also found that older and female respondents were less knowledgeable financially. Older respondents were also less willing to reveal their financial information. Compared to others, Black respondents were less willing to reveal their financial information, while Hispanics tended to do the opposite. Both education and cognitive ability were related to the financial knowledge in a predicted way, but education had no impact on respondent's willingness to reveal their financial information.

We did not find any statistically significant effect of total household assets on either respondents' financial knowledge or their willingness to reveal their knowledge. We did find, however, that respondents in coupled households were less knowledgeable financially and less willing to reveal their financial information; and that face-to-face interviewing might have a positive effect on respondents' willingness to reveal their financial information. 
Consistent with some other studies (e.g., Riphahn and Serfling, 2004), heterogeneity in respondents' financial knowledge and willingness to reveal the knowledge was found in our model. The assets about which respondents were least sure included bond and business and farm, while the assets about which respondents were most sure included checking and savings accounts and vehicle. The assets about which respondents did not want to reveal information the most included bond, $\mathrm{CD}$, and stock and mutual fund, while the assets about which they were most willing to reveal information included vehicle and debt.

\section{References}

AARP. (2002). AARP Vermont Financial Private Survey. Retrieved October 9, 2004, from http://research.aarp.org/consume/vt_privacy.pdf

Cao, H. (2001) "Impute: A SAS Application System for Missing Value Imputations, With Special Reference to HRS/AHEAD Income and Asset Imputations." HRS/AHEAD Documentation Report, Institute for Social Research, University of Michigan. Retrieved November 22, 2004, from http://hrsonline.isr.umich.edu/docs/userg/dr-007.pdf

Chand, H., and Gan, L. (2002). Wealth Item Nonresponse and Imputation in the AHEAD. Mimeo, Department of Economics, University of Texas, Austin. Retrieved October 10, 2004, from http://eco.utexas.edu/ gan/impute.pdf

Esser, H. (1993) “Response Set: Habit, Frame or Rational Choice?” In Krebs, D., and Schmidt, P. (eds.), New Directions in Attitude Measurement. Berlin: de Gruyter.

Essig, L., and Winter, J. (2003). Item Nonresponse to Financial Questions in Household Surveys: An Experimental Study of Interviewer and Mode Effects. Mannheim Research Institute for Economics of Aging, University of Mannheim. Retrieved October 9, 2004, from http://www.unibas.ch/wwz/stat/workshop/downloads/essigwinter.pdf

Fries, G., Starr-McCluer, M., and Sundén, A.E. (1998). The Measurement of Household Wealth using Survey Data: An Overview of the Survey of Consumer Finances. Retrieved October 10, 2004, from http://www.federalreserve.gov/pubs/oss/oss2/papers/overview.pdf

Groves, R.M., and Couper, M.P. (1989). Survey Errors and Survey Costs. New York: John Wiley and Sons.

Health and Retirement Study. (2004). "An Overview of Health and Retirement Study Components." Retrieved October 24, 2004, from 
http:/hrsonline.isr.umich.edu/docs/sho_refs.php?hfyle $=$ overview\&xtyp $=2$

Juster, F.T., and Smith, J.P. (1997). Improving the quality of economic data: Lessons from the HRS and AHEAD. Journal of the American Statistical Association, 92(440), 1268-1278.

Kim, J. (2001). Financial knowledge and subjective and objective financial well-being. Consumer Interests Annual, 47. Retrieved October 9, 2004, from http://www.consumerinterests.org/public/articles/Kim--Financial_knowledge.pdf

Knäuper, B., Belli, R., Hill, D., and Herzog, A. (1997) "Question Difficulty and Respondents' Cognitive Ability: The Effect of Data Quality.” Journal of Official Statistics, 13 (2), 181-199.

Loosveldt, G., Pickery, J., and Billet, J. (1999) "Item Non-Response as a Predictor of Unit NonResponse in a Panel Survey." Paper presented at the International Conference on Survey NonResponse, October, Portland, OR. Retrieved October 21, 2004, from http://www.jpsm.umd.edu/icsn/papers/loosveldt.htm

Murata, A., and Gwartney, P. "Question Salience, Question Difficulty and Item Nonresponse in Survey Research.” Mimeo, Oregon Survey Laboratory, retrieved October 22, 2004, from http://www.jpsm.umd.edu/icsn/papers/MurataGwartney1.htm\# ftn1

Riphahn, R.T., and Serfling, O. (2004). Item non-response on income and wealth questions. Retrieved October 9, 2004, from http://www.wwZ.unibas.ch/stat/team/riphahn/paper/ipanel05.pdf

Schräpler, J. (2004) "Respondent Behavior in Panel Studies: A Case Study for Income Nonresponse by Means of the German Socio-Economic Panel (SOEP)". Sociological Methods and Research, 33 (1), 118-156.

Sirken, M., Willis, G., and Nathan, G. (1991) "Cognitive Aspects of Answering Sensitive Questions.” In Proceedings of the International Association of Survey Statistics. Paris: International Statistical Institute.

Sudman, S., Bradburn, N. and Schwarz, N. (1996) Thinking about Answers. The Application of Cognitive Process to Survey Methodology. Jossey Bass Publishers, San Francisco.

Tourangeau, R. (1984) “Cognitive Science and Survey Methods.” In Jabine, T., Straf, A., Tanur, J., and Tourangeau, R. (eds.), Cognitive Aspects of Survey Methodology: Building a Bridge Between Disciplines. Washington, DC: National Academic Press.

Tourangeau, R., Rips, L., and Ransinki, K. (2000) The Psychology of Survey Response. Cambridge, UK: Cambridge University Press. 
Table 1. The Summary Statistics of the Variables Used

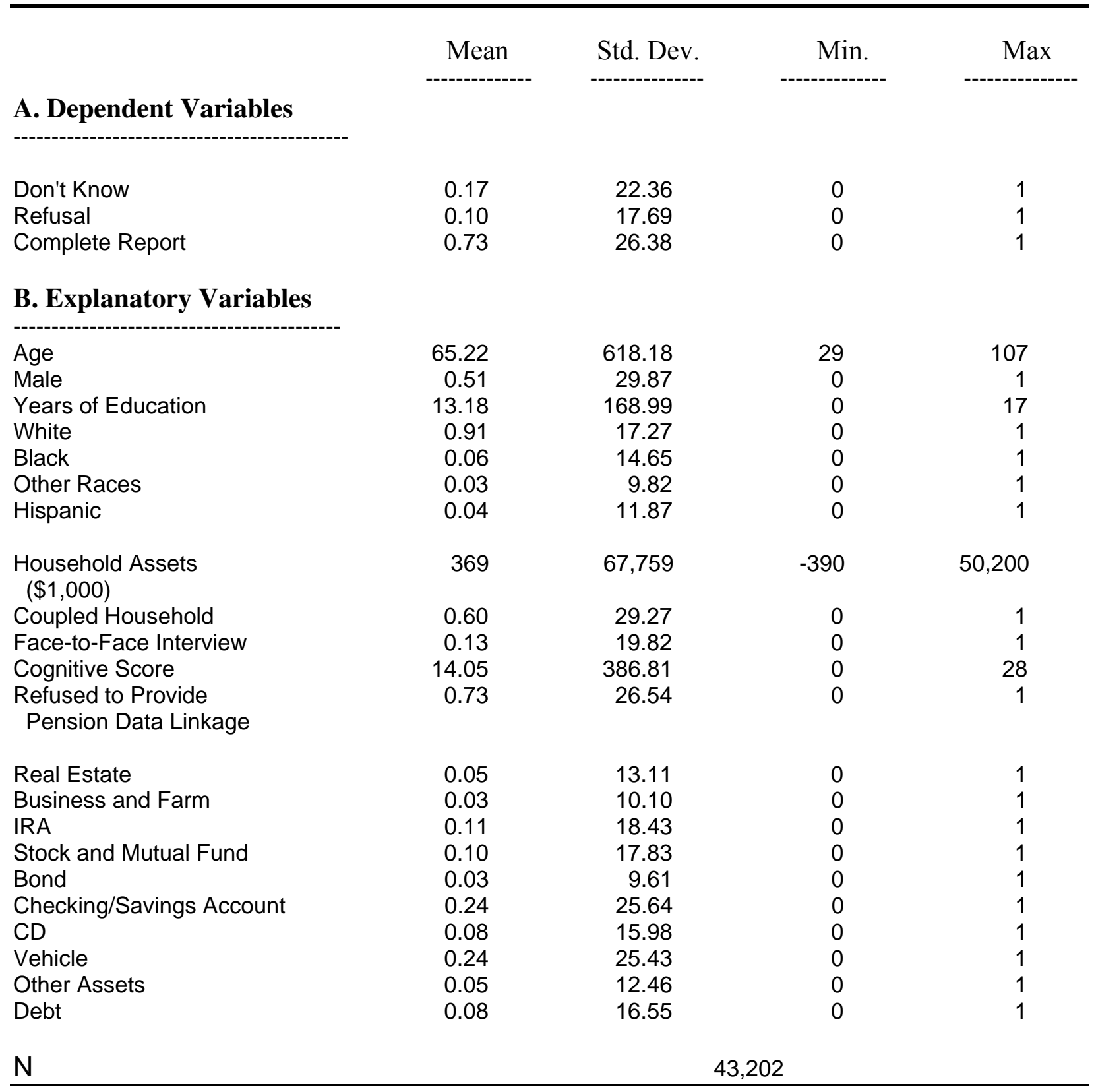


Table 2. Bivariate Probit Regression Results in the Knowledge and Preference Model

\begin{tabular}{|c|c|c|}
\hline & Don't Know & Refusal \\
\hline Age & $\begin{array}{l}.022^{\star *} \\
(.001)\end{array}$ & $\begin{array}{l}.009^{* *} \\
(.002)\end{array}$ \\
\hline Male & $\begin{array}{l}-.380^{\star *} \\
(.025)\end{array}$ & $\begin{array}{l}-.066 \\
(.040)\end{array}$ \\
\hline Years of Education & $\begin{array}{l}-.019 * * \\
(.004)\end{array}$ & $\begin{array}{l}-.003 \\
(.007)\end{array}$ \\
\hline White & $\begin{array}{l}-.145 \\
(.077)\end{array}$ & $\begin{array}{l}-.016 \\
(.136)\end{array}$ \\
\hline Black & $\begin{array}{l}.030 \\
(.082)\end{array}$ & $\begin{array}{l}.343^{*} \\
(.143)\end{array}$ \\
\hline Hispanic & $\begin{array}{l}.064 \\
(.062)\end{array}$ & $\begin{array}{l}-.364^{\star *} \\
(.109)\end{array}$ \\
\hline $\begin{array}{l}\text { Household Assets } \\
(\$ 1,000)\end{array}$ & $\begin{array}{l}-.000 \\
(.000)\end{array}$ & $\begin{array}{l}-.000 \\
(.000)\end{array}$ \\
\hline Coupled Household & $\begin{array}{l}.102^{\star \star} \\
(.025)\end{array}$ & $\begin{array}{l}.105^{\star \star} \\
(.040)\end{array}$ \\
\hline Face-to-Face Interview & $\begin{array}{l}-.043 \\
(.033)\end{array}$ & $\begin{array}{l}-.129 * \star \\
(.051)\end{array}$ \\
\hline Cognitive Score & $\begin{array}{l}-.020^{\star *} \\
(.002)\end{array}$ & \\
\hline $\begin{array}{l}\text { Refused to Provide } \\
\text { Pension Data Linkage }\end{array}$ & & $\begin{array}{l}.198^{\star \star} \\
(.047)\end{array}$ \\
\hline Real Estate & $\begin{array}{l}.437^{\star \star} \\
(.050)\end{array}$ & $\begin{array}{l}.178^{\star \star} \\
(.055)\end{array}$ \\
\hline Business and Farm & $\begin{array}{l}.925^{\star \star} \\
(.059)\end{array}$ & $\begin{array}{l}.298^{\star \star} \\
(.058)\end{array}$ \\
\hline IRA & $\begin{array}{l}.382^{\star *} \\
(.045)\end{array}$ & $\begin{array}{l}.417^{\star *} \\
(.048)\end{array}$ \\
\hline Stock and Mutual Fund & $\begin{array}{l}.710^{\star *} \\
(.044)\end{array}$ & $\begin{array}{l}.547^{\star \star} \\
(.045)\end{array}$ \\
\hline Bond & $\begin{array}{l}.753^{\star *} \\
(.059)\end{array}$ & $\begin{array}{l}.997^{\star \star} \\
(.053)\end{array}$ \\
\hline
\end{tabular}


Table 2. Continued

\begin{tabular}{|c|c|c|c|}
\hline Checking/Savings Account & $\begin{array}{l}.190 \star * \\
(.039)\end{array}$ & & $\begin{array}{l}.495^{\star *} \\
(040)\end{array}$ \\
\hline$C D$ & $\begin{array}{l}.362^{\star \star} \\
(.046)\end{array}$ & & $\begin{array}{l}.758^{* *} \\
(.045)\end{array}$ \\
\hline Vehicle & $\begin{array}{l}.391^{\star \star} \\
(.038)\end{array}$ & & $\begin{array}{l}-.430^{\star *} \\
(.047)\end{array}$ \\
\hline Other Assets & $\begin{array}{l}.542^{\star \star} \\
(.053)\end{array}$ & & $\begin{array}{l}.504^{\star *} \\
(.048)\end{array}$ \\
\hline \multicolumn{4}{|l|}{ Debt } \\
\hline Constant & $\begin{array}{c}-2.021^{\star *} \\
(.128)\end{array}$ & & $\begin{array}{c}-2.359 * \star \\
(.210)\end{array}$ \\
\hline athnh $\rho$ & & $\begin{array}{l}-1.97^{\star \star} \\
(.230)\end{array}$ & \\
\hline$\rho$ & & $\begin{array}{l}-.962^{\star *} \\
(.017)\end{array}$ & \\
\hline Log Likelihood & & $-1.074 \mathrm{e}+08$ & \\
\hline $\mathrm{N}$ & & 43,202 & \\
\hline
\end{tabular}

